\title{
A RARE GIANT URINARY BLADDER STONE IN AN ELDERLY MALE: A CASE REPORT
}

Braja Mohan Mishra1, Malay Krushna Nayak², Rabinarayan Guru33, Sandip Mishra4

\section{HOW TO CITE THIS ARTICLE:}

Braja Mohan Mishra, Malay Krushna Nayak, Rabinarayan Guru, Sandip Mishra. "A Rare Giant Urinary Bladder Stone in an Elderly Male: A Case Report". Journal of Evolution of Medical and Dental Sciences 2015; Vol. 4, Issue 20, March 09; Page: 3558-3561, DOI: 10.14260/jemds/2015/513

\begin{abstract}
A vesical calculus weighing more than $100 \mathrm{~g}$ is categorized as a giant urinary bladder stone. Male preponderance for urinary bladder calculi is well known. A large urinary bladder stone is more common in child.. A rare case of a giant bladder calculus weighing $565 \mathrm{~g}$ and occurring in a male patient is reported. The stone was removed by open cystolithotomy. Possible etiological factors are discussed, some of which are unique to this case.
\end{abstract}

KEYWORDS: Urinary bladder; Infection; Stone; Surgery.

INTRODUCTION: A giant vesical calculus weighing more than $100 \mathrm{~g}$ is an unusual finding in modern surgical practice.[1] Giant vesical stones are universally uncommon, and fewer than 30 reports of a stone that weighs more than $500 \mathrm{~g}$ are available in the English literature.[2] The most common causes of urinary bladder stone formation are well known: urinary tract infection (UTI), obstruction in the urinary tract that causes fluid stasis, enlargement of the prostate gland in men, and encrustation around foreign body that is present in the bladder.[3] Diet and the amount of fluid intake also appear to be important factors. ${ }^{[3]}$

CASE REPORT: A 42-year-old male presented with dysuria and burning micturation that had been occurring for the last 4-5 years. He described a feeling of heaviness and weight in the perineal region. His primary care physician in her village had been treating her for a UTI for the last 6 months.

EVALUATION: On examination, a nontender, firm lump was palpable in the suprapubic region. Per rectal examination revealed a hard, mobile mass in the urinary bladder. There were multiple red blood cells and white blood cells in the urine. Urine culture showed Escherichia coli. Total leukocyte counts were raised. The remaining investigations were within normal limits. The patient was put on third-generation cephalosporin antibiotics with amikacin and metrogyl, bladder irrigation was done for $72 \mathrm{hrs}$.Repeat routine urine examination revealed white blood cell-2-3/hpf. A plain X-ray of the abdomen revealed a large radiopaque shadow in the pelvic region Figure 1.

SURGICAL MANAGEMENT AND FOLLOW-UP: A huge stone that was brownish-white in color with fine spicules on its surface was removed through suprapubic cystolithotomy Figure II. The urinary bladder layer was closed in 2 layers with Vicryl 2-0 sutures; the sheath was closed with Vicryl 1-0 (Ethicon). The skin was closed with Ethilon 2-0 with a drain in space of retzius. A three way Foley catheter was inserted through the urethra.

The stone weight was $565 \mathrm{~g}$ and its size was $8 \mathrm{~cm} \times 9.8 \mathrm{~cm} \times 6 \mathrm{~cm}$ Figure 3. Post op period was uneventful, all kin stitches removed on $7^{\text {th }}$ post op day. 


\section{CASE REPORT}

DISCUSSION: A urinary bladder stone is usually defined as a giant calculus when its weight is $>100$ g.[1,4] Urinary bladder calculi constitute $5 \%$ of all urolithiases. ${ }^{[5]}$ The incidence of adult male urinary lithiasis is very low;. Most vesical calculi are composed of triple phosphate, calcium carbonate, and calcium oxalate (as in the present case).

Aside from the UTI, the predisposing factors that may have caused the bladder stone in the present case were unique. The patient came from a very remote, inaccessible village that lacked a basic medical diagnostic facility with X-ray and ultrasound technology. Such technology may have been used to find the calculus when it was smaller in size. The patient also had dietary problems along with reduced fluid intake. These factors probably compounded the UTI and resulted in the formation of the giant calculus.

Giant bladder stones are commonly precipitated by development of bladder diverticulum, benign prostatic hypertrophy in males, or genital prolapsed in females.[7] Prolonged catheterization, neurogenic bladder, a foreign body, and trauma are other rare causes. Promerantz et al[6] reported a rare case of a urinary bladder calculus that formed around an arterial graft and was incorporated into the bladder. It is thought that a giant vesical calculus develops from the nidus of the infected material or from a single ureteric calculus with progressive layer-wise deposition of calcified matrix. Thus, each of the previously stated factors may contribute to the formation of the calculus. ${ }^{[8]}$ In addition, Schwartz and Stoller ${ }^{[3]}$ indicated that infection may not be the inciting factor in stone formation, but may play a major role in further stone crystallization.

The diagnosis of vesical calculi requires a high index of suspicion. A history of suprapubic pain that is aggravated by exercise, an interruption of the urinary stream, and terminal hematuria are helpful but not pathognomonic of the disease because they may be caused by other lesions in the bladder. A large stone may be palpable on rectal, vaginal, or abdominal examination, but it is difficult to diagnose a stone through physical examination alone. "Sounding" the bladder stone by feeling it "clink" on a urethral sound is an age-old technique for detecting bladder stones, but this procedure has been replaced by more modern methods. ${ }^{[1,2]}$ Abdominal X-ray and ultrasound may be helpful, but cystoscopic examination provides definitive diagnosis. ${ }^{[2]}$

CONCLUSION: Bladder calculi are an uncommon cause of illness in most Western countries, but their presence results in specific symptoms and cause a significant degree of discomfort. Physicians should be alert to the possibility of a urinary bladder stone in patients presenting with urinary symptoms. Because obstructive lesions and infection seem to play a role in the formation and growth of vesical calculi, their eradication will minimize the occurrence of stones. These patients should be examined as soon after symptoms appear as possible to rule out underlying disease or other causes. Patients who have small stones should be followed with regular examinations to prevent development of giant calculi.

\section{REFERENCES:}

1. Becher RM, Tolia BM, Newman HR. Giant vesical calculus. JAMA. 1978; 239(21): 2272-2273.

2. Rahman GA, Akande AA, Mamudu NA. Giant vesical calculi: experience with management of two Nigerians. Nigerian J Surg Res. 2005; 7: 203-205.

3. Schwartz BF, Stoller MZ. The vesical calculus. Urol Clin North Am. 2000; 27: 333-346. 


\section{CASE REPORT}

4. Di Tonno F, Forte M, Guidoni E, Cavazzana A, Barbui P. A giant bladder stone. Br J Urol. 1988; 62(1): 90-91.

5. Pomerantz PA. Giant vesical calculus formed around arterial graft incorporated into bladder. Urology. 1989; 33(1): 57-58.

6. Beisland C, Andersen M. Giant urinary bladder stone [in Norwegian]. Tidsskr Nor Laegeforen. 2000; 120(5): 573-574.

7. Williams JP, Mayo ME, Harrison NW. Massive bladder stone. Br J Urol. 1977; 49(1): 51-56.

8. Leach GE, Fitzpatrick TJ. Giant vesical calculi in the female. Urology. 1981; 17(3): 274-275.

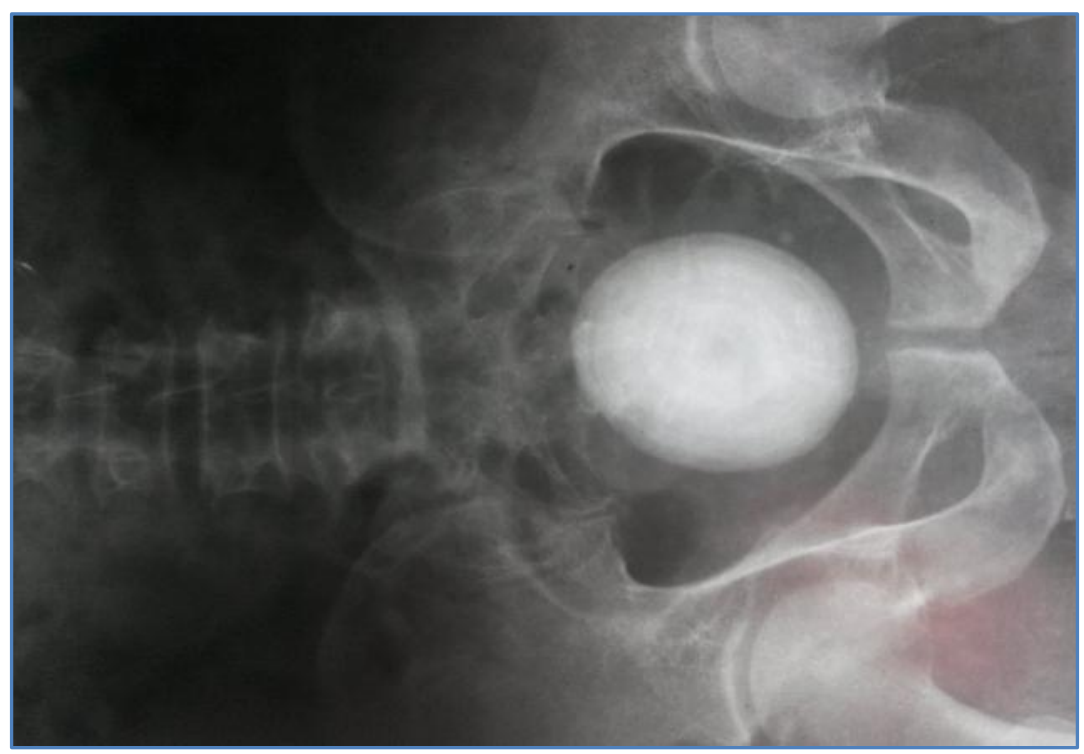

Fig. 1

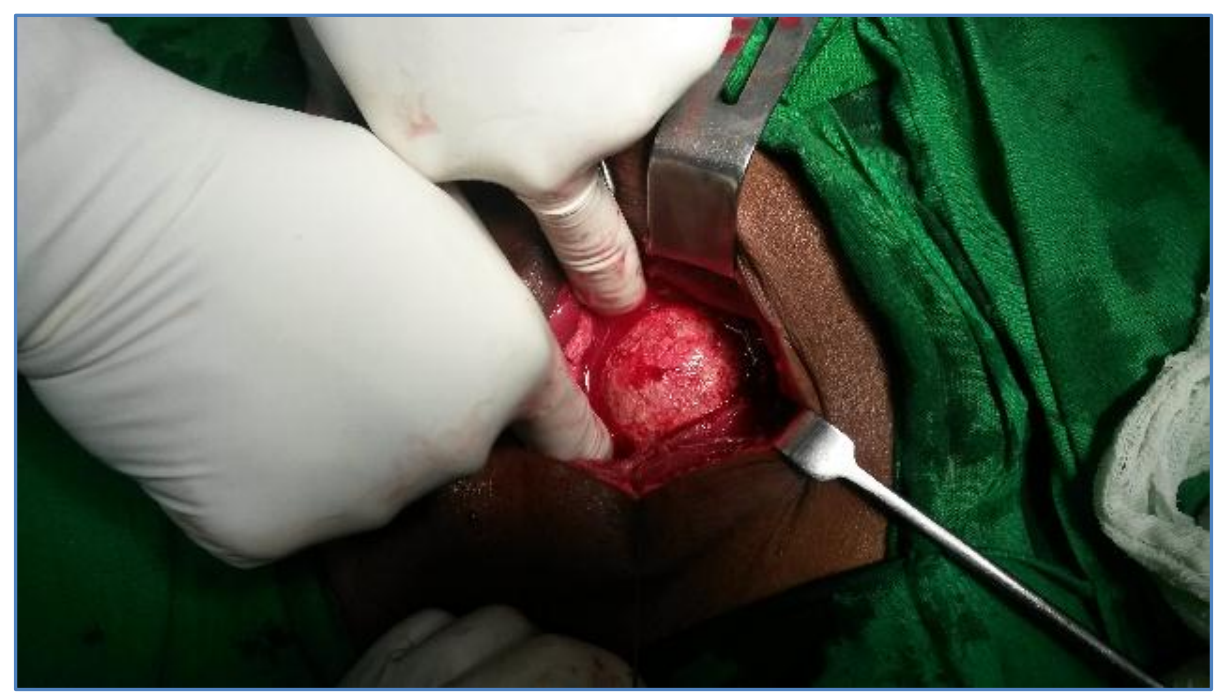

Fig. 2 


\section{CASE REPORT}

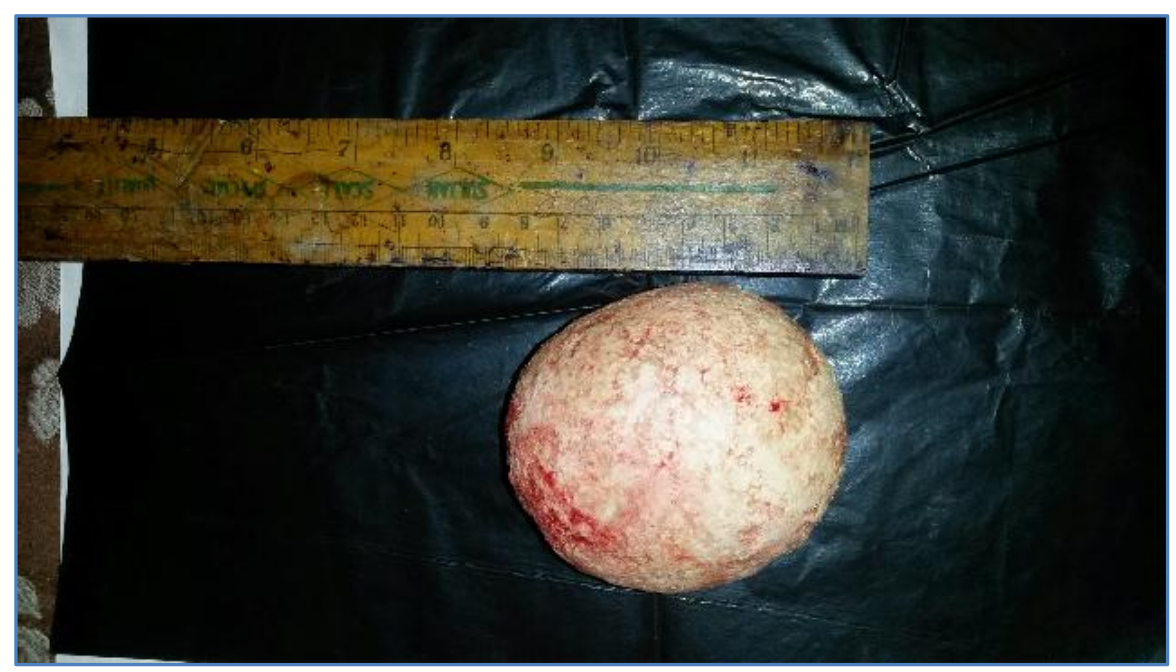

Fig. 3

\section{AUTHORS: \\ 1. Braja Mohan Mishra \\ 2. Malay Krushna Nayak \\ 3. Rabinarayan Guru \\ 4. Sandip Mishra}

\section{PARTICULARS OF CONTRIBUTORS:}

1. Professor, Department of Surgery, VSS Medical College, Burla, Odisha.

2. Assistant Professor, Department of Surgery, VSS Medical College, Burla, Odisha.

FINANCIAL OR OTHER

COMPETING INTERESTS: None
3. Post Graduate Student, Department of Surgery, VSS Medical College, Burla, Odisha.

4. Post Graduate Student, Department of Surgery, VSS Medical College, Burla, Odisha.

\section{NAME ADDRESS EMAIL ID OF THE CORRESPONDING AUTHOR:}

Dr. Rabinarayan Guru, Post Graduate Student, Department of Surgery, VSS Medical College, Burla-768017, E-mail: rnguru1976@gmail.com

Date of Submission: 06/02/2015. Date of Peer Review: 07/02/2015. Date of Acceptance: 26/02/2015. Date of Publishing: 09/03/2015. 